\title{
The Weather Risk Management: is it a Research Area for "Weather Scientist" or for "Economical Scientist"?
}

\section{Alessandro Pezzoli*}

${ }^{1}$ Politecnico di Torino, Department of Environment, Land and Infrastructure Engineering, Corso Duca degli Abruzzi n. 24, 10129, Torino, Italy

This editorial comes from the need to analyze a new multidisciplinary research area in the meteorological science: the Weather Risk Management (WRM).

First of all, it is useful to define what risk is. To give an answer about this question, we can use the definition as reported in the Project Management Body of Knowledge (PMBOK) [1]. In the PMBOK is possible to read that: “.... Risk is an uncertain event or condition that, if it occurs, has an effect on at least one project objective. Objectives can includes scope, schedule, cost, and quality. A risk may have one or more causes and, if it occurs, it may have one or more impacts. A cause may be a requirement, assumption, constraints, or condition that creates the possibility of negative or positive outcomes.... If either of these uncertain events occurs, there may be an impact on the project cost, schedule or performance....".

It is evident as the risk is the quantification of the possibility that adverse and uncertain events, associated with operational and financial consequences, will occur.

Focusing on the words "adverse" and "uncertain", it can be natural to think how the weather can be one of the events that it creates the risk. In agreement with Dutton [2], it possible to define the weather and climate risk as "the possibility of injury, damage to property, or financial loss owing to severe or extreme weather events, unusual season variations such as heat waves or droughts, or long-term changes in climate or climate variability".

Analyzing these definitions help us to understand how the weather risk brings together different scientific disciplines as the economics (business at risk), project management (plan of risk management and strategies of risk management), statistic (data mining) and meteorology (weather observations, meteorological modeling and weather finance).

The sectors, where the weather impacts on business revenues, are added, in turn, to the previous description main areas of knowledge. In the first time and in agreement with Tang [3], it possible to define the following sectors:

- Energy

- Agriculture

- Entertainment

- Retailing

- Constructions

- Transportations/Logistic

- Travel

- Manufacturing

- Local Governments

- Insurance

Looking the impact of weather on business and the rationale of hedging [4] as well as the economic value of the weather forecast [5], it is clear that new sectors and new industrial activities "open the door" and enter in the WRM scientific area.

In fact Pezzoli and Franza [6] demonstrated how the static cost-loss ratio model [5] can be used to manage the advertising industry that it can be weather affected.

Right now the Sports' Industry is studied to understand if and when it can be exposed to weather risk and then it can be interested at "Weather Derivatives". First of all, the "Sports Industry" can be divided in three main sectors (excluded the Sports Factory and Production):

1. Leisure

2. Event

3. Performance

It is quite evident how, in "Leisure" as well as in the "Event", the weather derivatives can be used to transfer "financial" risks associated with weather uncertainty. It is clear as these sectors enter directly in the above mentioned sector of the Entertainment where the impact of weather on business revenues is linked with the postponements of the event and with the reduced attendance [3,7].

However it is important to focus "if and how" you can apply the same methods for the Sports Performance. It is evident that if we concentrate only on the last part of a performance, so on the race, for sure this isn't an argument that can be analyzed with the methods of Weather Risk Management.

But it is well recognized, in the sports community, that an excellent performance is led by an effective training period. Organizing good period of training is a matter for "Weather Derivatives".

During my long experience in America's Cup Campaign (sail boat) as well as in F1 as "Weather Strategist", I see how the weather derivatives can be used to transfer "financial" risks associated with weather uncertainty.

In Valencia we had to decide, six months before the training, the location where we had to move for the winter training choosing between four locations around the world in function of a statistical analysis of the expected weather conditions. In this case, the cost of

*Corresponding author: Alessandro Pezzoli, Politecnico di Torino, Department of Environment, Land and Infrastructure Engineering, Corso Duca degli Abruzzi n. 24 10129, Torino, Italy, Tel: 00393472221638; E-mail: alessandro.pezzoli@polito.it

Received April 17, 2013; Accepted April 17, 2013; Published April 22, 2013

Citation: Pezzoli A (2013) The Weather Risk Management: is it a Research Area for "Weather Scientist" or for "Economical Scientist"? J Climatol Weather Forecasting 1: e103. doi:10.4172/2332-2594.1000e103

Copyright: () 2013 Pezzoli A. This is an open-access article distributed under the terms of the Creative Commons Attribution License, which permits unrestricted use, distribution, and reproduction in any medium, provided the original author and source are credited. 
Citation: Citation: Pezzoli A (2013) The Weather Risk Management: is it a Research Area for "Weather Scientist" or for "Economical Scientist"? J Climatol Weather Forecasting 1: e103. doi:10.4172/2332-2594.1000e103

Page 2 of 2

the operation to move the America's Cup boat and the Team is around millions of Euros.

The same was also to manage a day of training because if we had a bad forecast and we decided to training in the bad "part" of the day, we lost around $100,000 €$ (direct and indirect costs) The same is for the Formula 1 where the training are under quota and you have to choose the good period in the good place. I had a very interesting experience in the past February (2012) for a training period of a F1 Team when we prepared the forecast using the Ensemble methods helping the Team Manager to decide if go ahead or stop the planned training.

It is clear how the Sport Industry can be an important area of application for the weather derivatives as well as for the weather risk decision making process. In fact, these examples show us how the weather can affect the daily decision, taken by the team manager or coach, about whether or not to direct the team to train on that day. This decision problem is characterized by several features, including:

- The decision must be taken before that the daily weather conditions are entirely known, on the basis of a forecast

- Once a daily decision is made, it is difficult or impossible to reverse

- If the decision is "Yes, let's train!", then substantially expensive resources are deployed towards the training exercise

- The feasibility and quality of the training experience is strongly influenced by weather: if the weather turns bad, much of this expense is wasted

- Effective training requires that a certain minimum number of good training days have to be held over the course of the training season

- The total financial budget for the training season is limited.

It is evident how the data-driven approach, to making these daily "Go/No-Go" decisions over the course of a season, can be derived from other areas of application closest to the WRM [8].
Finally it is clear how the Weather Risk Management is a research area not only for "weather scientist" or for "economical scientist" including multi-disciplinary issues as the data-mining, statistic, mathematic, operational research as well as the knowledge of the disciplines subject of the study and application (i.e.: Energy, Agriculture, Sports, etc...).

In this perspective a multi-disciplinary Journal, as Advance Research in Meteorological Sciences (ARMS), can serve the scientific community looking to a "new way" where different disciplines merge to study and analyze how the weather can affect the business and the economics.

\section{Acknowledgements and Disclaimers}

Alessandro Pezzoli, BEng, MEng, MSc, PhD is an ARMS Editorial Board member and Adjoint Professor (Senior Lecturer) in Meteo-Hydrology and Weather Risk Management in the Politecnico di Torino and in the University of Torino as well as Scientific Adviser of R.U. Meteo Sport-Department of Sport Psychology - Sport Science Research Centre - University of Turin.

\section{References}

1. AA VV (2008) Project Management Body of Knowledge - PMBOK Guide. Ed. Project Management Institute, Pennsylvania - USA.

2. Dutton JA (2002) Opportunities and priorities in a new era for weather and climate services. American Meteorological Society, September.

3. Tang Kenny (2010) Weather Risk Management. A guide for Corporations, Hedge Fund and Investors, Risk Books, London, UK.

4. Jewson S, Brix A (2005) Weather derivatives valuation. The Meteorological, Statistical, Financial and Mathematical Foundations, Cambridge University Press, Cambridge, UK.

5. Katz RW, Murphy AH (1997) Economic Value of Weather and Climate Forecast Cambridge University Press, Cambridge, UK.

6. Pezzoli A, Franza M (2003) Rainfall forecast in tropical-equatorial environments: a case study of the Seychelles zone. Meteorological Applications 10: 101-110.

7. Pallotta M, Pezzoli A, Herdies DL, de Gonçalves LGG (2012) Meteorologia AplicadaaoEsporte: umestudo de caso.

8. Small AA, Stefik JB, Verlinde J, Johnson NC (2011) The Cloud Hunter's Problem: An Automated Decision Algorithm to Improve the Productivity of Scientific Data Collection in Stochastic Environments. Mon Wea Rev 139 2276-2289. 